\title{
S100 calcium-binding protein A4 is a novel independent prognostic factor for the poor prognosis of gastric carcinomas
}

\author{
YING ZHAO $^{1}$, TIANBIAO ZHANG ${ }^{2}$ and QIANG WANG $^{1}$ \\ ${ }^{1}$ Department of General Surgery, Shengjing Hospital of China Medical University, Shenyang, Liaoning 110004; \\ ${ }^{2}$ Department of Biochemistry and Molecular Biology, College of Basic Medicine, \\ China Medical University, Shenyang, Liaoning 110001, P.R. China
}

Received January 15, 2013; Accepted March 5, 2013

DOI: $10.3892 / o r .2013 .2419$

\begin{abstract}
Overexpression of the S100 calcium-binding protein A4 (S100A4) is involved in epithelial-to-mesenchymal transition, oncogenic transformation, angiogenesis, cytoskeletal integrity and cancer metastasis. Here, we elucidated the role of S100A4 in tumorigenesis and progression of gastric carcinomas. S100A4 expression in gastric carcinomas, adenomas and adjacent non-neoplastic mucosa was analyzed by immunohistochemical, real-time reverse transcriptase (RT)-polymerase chain reaction (PCR) and western blot analyses, and was correlated with various clinicopathological parameters. S100A4 protein expression was increased gradually in the following order: gastritis (19.2\%), intestinal metaplasia (IM; 23.3\%), dysplasia (34.9\%) and carcinoma $(55.2 \%$; $\mathrm{P}<0.001)$. S100A4 was positively correlated with tumor size, depth of invasion, lymphatic invasion, lymph node metastasis and tumor-node-metastasis $(\mathrm{TNM})$ staging $(\mathrm{P}<0.05)$, but not with the age and gender of the carcinoma patients $(\mathrm{P}>0.05)$. Intestinal-type (IT) carcinomas showed a higher S100A4 expression than diffuse-type (DT) carcinomas $(\mathrm{P}<0.001)$. S100A4 mRNA expression also increased in the following order: gastritis < IM < dysplasia < carcinoma $(\mathrm{P}<0.05)$. S100A4 overexpression was observed in gastric carcinomas with a larger diameter, deeper invasion, lymph node metastasis and in IT carcinoma $(\mathrm{P}<0.05)$. Univariate analysis using the Kaplan-Meier method indicated a lower cumulative survival rate for patients with weak or moderate S100A4 expression compared with patients not expressing S100A4 $(\mathrm{P}<0.001)$. Multivariate analysis using Cox's proportional hazard model demonstrated that depth of invasion, lymphatic or venous invasion, lymph node metastasis, TNM staging and S100A4 expression were independent factors for poor patient prognosis $(\mathrm{P}<0.05)$. In conclusion, S100A4 upregulation is positively associated with the pathogenesis, growth, invasion, metastasis
\end{abstract}

Correspondence to: Professor Qiang Wang, Department of General Surgery, Shengjing Hospital of China Medical University, Shenyang, Liaoning 110004, P.R. China

E-mail: f20462012@126.com

Key words: gastric carcinoma, S100A4, pathogenesis, progression, prognosis and differentiation of gastric carcinomas. S100A4 may be a promising marker indicative of the aggressive behavior and prognosis of gastric carcinomas.

\section{Introduction}

Gastric carcinoma is the second leading cause of cancerrelated mortality in the world (1), after lung cancer. Despite a sharp worldwide decline in both the incidence and mortality of gastric carcinoma since the second half of the $20^{\text {th }}$ century, it still continues to be a major health problem worldwide. This can be attributed to the particularly slow decrease in the incidence of gastric carcinoma in Asia and a high mortality rate of the diagnosed gastric carcinoma cases in the West (2). Therefore, research efforts that elucidate the molecular mechanisms underlying gastric carcinogenesis and subsequent disease progression and that identify reliable biomarkers are of critical importance for the prevention, treatment, and prognostic evaluation of gastric cancer.

The S100 proteins are calcium-binding, acidic, lowmolecular-weight proteins (10-12 kDa), which are named according to their solubility in $100 \%$ saturated ammonium sulfate. In recent years, these proteins are gaining importance due to their association with diseases such as cardiomyopathy, neurodegenerative disorders and cancer (3). The S100 protein family includes $\sim 25$ members, with the genes clustered on human chromosome 1q21. The encoded proteins contain two EF-hand calcium-binding helix-loop-helix motifs. Each member contains two EF-hands connected by a central hinge, which is S100 family-specific in the N-terminus and canonical in C-terminus (4). Overexpression of the S100 calcium-binding protein A4 [S100A4, also known as Mts1 (metastasis-associated gene), p9Ka, 18A2, pEL98, 42A, CAPL and calvasculin] of the S100 protein family has been shown to control cell cycle progression and modulate intercellular adhesion, as well as invasive and metastatic properties of cancer cells (5). The human S100A4 gene is located at position 1q21 on chromosome 1 and encodes a polypeptide of 101 amino acids with a molecular mass of $\sim 11.5 \mathrm{kDa}$ (6). The S100A4 gene contains four exons, and its open reading frame begins from the third exon. The S100A4 promoter contains an ErbB2 response element, and the enhancer and silencer elements of the S100A4 gene may be strongly affected by methylation $(7,8)$. 
The S100A4 protein has been shown to be present at detectable limits in a subset of cells of the ovary, prostate, spleen, thymus, bone marrow, T lymphocytes, neutrophils and macrophages, whereas very low levels have been detected in normal tissues of the pancreas, colon, thyroid, lungs and kidneys (8). S100A4 overexpression has been reported to be positively correlated with rheumatoid arthritis, kidney fibrosis, liver fibrosis, peritoneal fibrosis, corneal dystrophy, neural diseases, and cardiac and lung disease (7,8). Furthermore, S100A4 overexpression is involved in epithelial-to-mesenchymal transition (EMT), oncogenic transformation, and aggressive progression of cancers $(9,10)$. Transgenic mice that overexpress S100A4 in the mammary epithelium are phenotypically indistinguishable from wild-type mice and exhibit increased metastasis (11). Inhibition of S100A4 (by antisense or anti-ribozyme approaches) suppressed the metastatic potential of tumor cells in animal models of lung carcinoma and osteosarcoma $(12,13)$. Several proteins have been identified as targets for the S100A4 protein, including liprin $\beta 1$ and methionine aminopeptidase (14). S100A4 is reported to bind to the C-terminal regulatory domain of p53 in vitro and inhibit its phosphorylation, thus suppressing the transcription of p53 target genes including p21/WAF, Bax, thrombospondin-1 and Mdm-2 (15). S100A4 is also known to interact with proteins involved in cytoskeletal rearrangement and cell motility such as F-actin, myosin-IIA, tropomyosin, and the heavy chain of nonmuscle myosin II (16-18). Additionally, S100A4 has been shown to exhibit its prometastatic role through its influence on angiogenesis, cytoskeletal integrity, matrix metalloproteinases (MMPs), tumor-related transcription factors and stromal factors $(19,20)$.

The aim of the present study was to analyze S100A4 expression in gastric cancer and precancerous lesions at both the protein and mRNA levels and to further compare this S100A4 expression with the clinicopathological features of gastric cancer.

\section{Materials and methods}

Patients and tissue specimens. Gastric cancer tissue was collected from gastrectomy specimens and from gastritis, gastric intestinal metaplasia (IM), and adenoma specimens by endoscopic biopsies performed between January 1995 and January 2005 at Department of General Surgery, Shengjing Hospital of China Medical University. The tissues were fixed in $10 \%$ neutral formalin, embedded in paraffin, and cut into $4-\mu \mathrm{m}$ sections. The sections were stained by hematoxylin and eosin (H\&E) to confirm histological diagnosis and other microscopic characteristics. Portions of a few samples were frozen in liquid nitrogen until the tissue was homogenized for RNA and protein extraction. The tumor-node-metastasis (TNM) staging for each gastric carcinoma specimen was performed according to the Union Internationale Contre le Cancer (UICC) system for the extent of tumor spread (21). Histological architecture of the gastric carcinoma was expressed in terms of Lauren's classification (22,23). Furthermore, tumor size, depth of invasion, and lymphatic and venous invasion were determined. Lymphatic and venous invasion were assessed first by H\&E staining, followed by D2-40 immunostaining (for lymphatic invasion) and EvG staining (for venous invasion), if necessary. None of the patients underwent chemotherapy, radiotherapy, or adjuvant treatment before surgery. The University Ethics Committee of China Medical University approved the research protocol. The patients were carefully followed up by consulting their case documents and through telephone monitoring.

Tissue microarray (TMA) and immunohistochemistry. Representative areas of the solid tumors were identified in the H\&E-stained sections of the selected tumor cases, and a tissue core ( $2 \mathrm{~mm}$ in diameter) per donor block was punched out and transferred to a recipient block with a maximum of 48 cores using a manual arraying device (MTA-1; Beecher Instruments, Inc., Sun Prairie, WI, USA). Sections (4- $\mu \mathrm{m})$ were consecutively incised from the recipient block and transferred to poly-lysine-coated glass slides. H\&E staining was performed on the TMA sections for confirmation of the tumor tissue.

Immunohistochemistry was performed on $4-\mu \mathrm{m}$ formalinfixed, paraffin-embedded tissue sections. The sections were first deparaffinized in xylene and rehydrated through graded concentrations of alcohol. For antigen retrieval, endogenous peroxidase activity was blocked by incubating the slides in $1.5 \%$ hydrogen peroxide in absolute methanol at room temperature for $10 \mathrm{~min}$. Next, the sections were subjected to antigen retrieval by heating the slides in target retrieval solution (TRS; Dako) for $15 \mathrm{~min}$ in a microwave oven (Oriental Rotor Ltd. Co., Tokyo, Japan). The rabbit polyclonal antibody against S100A4 (Abcam, Cambridge, UK; 1:200) was applied for $1 \mathrm{~h}$ at room temperature, according to the manufacturer's instructions, and the sections were washed three times with TBST. After a final rinse with TBST, the sections were further incubated with an anti-rabbit IgG antibody conjugated to horseradish peroxidase (Dako) at a dilution of 1:1,000 for $1 \mathrm{~h}$. The final color was visualized by exposing the sections to $0.5 \mathrm{mg} / \mathrm{ml} \mathrm{3,3'-diamino-}$ benzidine and $0.005 \%$ hydrogen peroxide for $\sim 5 \mathrm{~min}$. After counterstaining with Mayer's hematoxylin, the sections were dehydrated, cleared and mounted. Sections without the addition of the primary antibody were used as a negative control.

The slides were randomly allocated for analysis by two independent experienced pathologists with no knowledge of the clinicopathological data. For each slide, the number of S100A4positive cells was counted in 10 fields at x200 magnification, and the percentage of positively stained cells was determined. The percentage of positively stained cells was graded semiquantitatively according to a four-point scoring system as follows: negative (-), 0-5\%; weakly positive $(+), 6-25 \%$; moderately positive (++), 26-50\%; and strongly positive (+++), $>50 \%$.

Real-time reverse transcriptase (RT)-polymerase chain reaction $(P C R)$. Total RNA was extracted using the TRIzol ${ }^{\circledR}$ reagent (Invitrogen, Carlsbad, CA, USA), and cDNAs were reverse transcribed by the RevertAid ${ }^{\mathrm{TM}}$ RT (Takara Bio, Inc., Otsu, Shiga, Japan). Real-time PCR was carried out using the ABI PRISM $^{\circledR} 7500$ Sequence detection system (Applied Biosystems, Foster City, CA, USA) at $50^{\circ} \mathrm{C}$ for $2 \mathrm{~min}, 95^{\circ} \mathrm{C}$ for $10 \mathrm{~min}$, followed by 50 cycles at $95^{\circ} \mathrm{C}$ for $15 \mathrm{sec}$, and at $60^{\circ} \mathrm{C}$ for $1 \mathrm{~min}$. The primers for glyceraldehyde-3-phosphate dehydrogenase (GAPDH; 135 bp, 201-335, NM_002046.3) were 5'-CAATGACCCCTTCATTGACC-3' (sense) and 5'-TGGAA GATGGTGATGGGATT-3' (antisense). The primers for S100A4 (130 bp, 248-377, NM_019554.2) were 5'-AGCTTCT TGGGGAAAAGGAC-3' (sense) and 5'-TACACATCATGG 


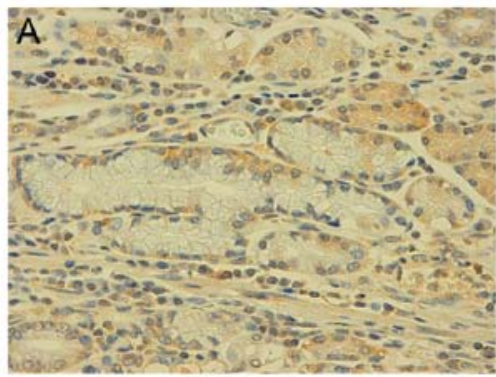

Gastritis

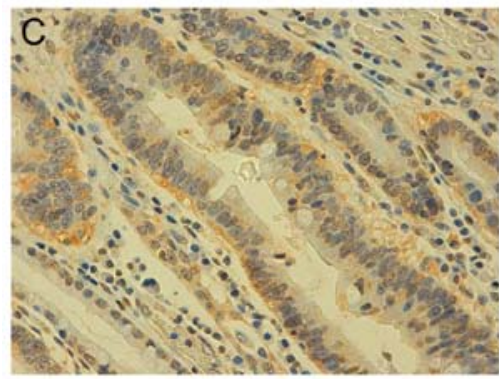

Adenoma

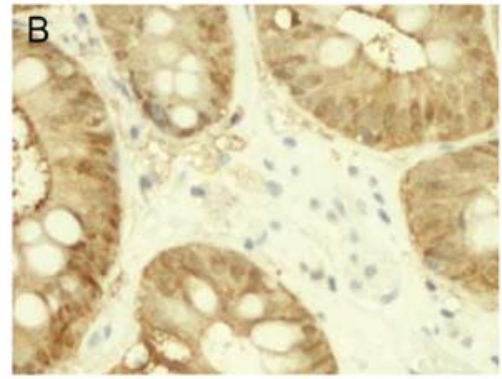

Intestinal metaplasia

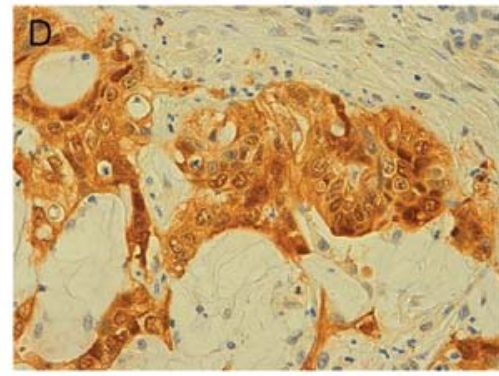

Adenocarcinoma

Figure 1. Immunohistochemical staining of the S100A4 protein in gastric lesions. The S100A4 protein was positively expressed in the cytoplasm of cells obtained from (A) gastritis, (B) intestinal metaplasia, (C) adenomatous dysplasia and (D) carcinoma specimens (magnification, x100).

CGATGCAG-3' (antisense). Expression of GAPDH was used to normalize expression of the target genes. Each assay was performed in triplicate, the average was calculated, and the expression level of S100A4 was expressed as $2^{-\Delta \Delta \mathrm{Ct}}$, where $\Delta \mathrm{Ct}=\mathrm{Ct}(\mathrm{S} 100 \mathrm{~A} 4)-\mathrm{Ct}(\mathrm{GAPDH}) . \Delta \Delta \mathrm{Ct}=\Delta \mathrm{Ct}($ carcinoma $)-\Delta \mathrm{Ct}$ (mucosa).

Western blot analysis. Protein was extracted by homogenizing

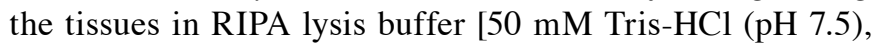
$150 \mathrm{mM} \mathrm{NaCl}, 5 \mathrm{mM}$ EDTA, 0.5\% Nonidet P-40, $5 \mathrm{mM}$ dithiothreitol, $10 \mathrm{mM} \mathrm{NaF}$, protease inhibitor cocktail] (Sigma, St. Louis, MO, USA), and the amount of protein was concentrated by the bicinchoninic acid (BCA) method. The denatured proteins were separated on a $15 \%$ SDS-polyacrylamide gel and transferred to a Hybond-P PVDF membrane (Amersham plc, Amersham, Germany), which was then blocked overnight in 5\% skim milk in TBST $(10 \mathrm{mmol} / \mathrm{l}$ Tris- $\mathrm{HCl}, 150 \mathrm{mmol} / \mathrm{l}$ $\mathrm{NaCl}, 0.1 \%$ Tween-20). For immunoblotting, the membrane was incubated for $1 \mathrm{~h}$ with the rabbit antibody against S100A4 (1: 500). The membrane was rinsed with TBST and incubated with an anti-rabbit or anti-mouse secondary IgG conjugated to horseradish peroxidase (1:1,000; Dako, Carpinteria, CA, USA) for $1 \mathrm{~h}$. Bands were visualized on X-ray film (Fuji, Japan) using the ECL Plus detection reagents (Santa Cruz Biotechnology, Inc., Santa Cruz, CA, USA). Next, the membrane was washed with the WB Stripping Solution (pH 2.0-3.0; Nacalai, Tokyo, Japan) for $1 \mathrm{~h}$ and treated as described above, except an antiGAPDH antibody (1:10,000; Sigma) was used as an internal loading control. Densitometric quantification of the S100A4 protein in gastric samples was performed using on Scion Image software (Scion Corporation, Frederick, MD, USA) using GAPDH as a control.

Statistical analyses. All quantitative data are expressed as means \pm standard deviation (SD). The Student's t-test and one-way analysis of variance (ANOVA) with the Student'sNewman-Keuls t-test were used to compare the means of different groups. Categorical data were analyzed by the Spearman's correlation test. Kaplan-Meier survival plots were generated, and comparisons between survival curves were carried out with log-rank statistics. Cox's proportional hazards model was employed for multivariate analysis. SPSS 10.0 software (SPSS Inc., Chicago, IL, USA) was used to analyze all data, and $\mathrm{P}<0.05$ was considered to indicate a statistically significant result.

\section{Results}

Immunohistochemical analysis for S100A4 expression in gastric carcinomas. The expression of the S100A4 protein was assessed by determining the number of positively stained tumor cells using a four-point scoring system, as described in Materials and methods. As shown in Fig. 1, S100A4 was positively immunostained in the cytoplasm and nuclei of gastric epithelial cells, IM, adenomatous dysplasia, and carcinoma cells. Overall, S100A4 expression was detected in $19.2 \%$ of the gastritis cases (14/73), $23.3 \%$ of the IM cases (20/86), $34.9 \%$ of the adenomatous dysplasia cases (22/63), and $55.2 \%$ of the total gastric carcinoma cases (192/348). Based on the S100A4 expression frequency and density, we inferred that there was a gradual increase in S100A4 expression in the following order: gastritis $<$ IM $<$ dysplasia $<$ carcinoma $(\mathrm{P}<0.001)$ (Table I).

Correlation between S100A4 expression and clinicopathological factors. Next, we analyzed the correlation between positive S100A4 expression and various clinicopathological factors that may affect the prognosis of patients with gastric carcinoma. As summarized in Table II, S100A4 expression was positively correlated with tumor size, depth of invasion, 
Table I. S100A4 expression in gastric carcinogenesis.

\begin{tabular}{|c|c|c|c|c|c|c|c|}
\hline \multirow[b]{2}{*}{ Groups } & \multirow[b]{2}{*}{$\mathrm{N}$} & \multicolumn{4}{|c|}{ S100A4 expression } & \multirow[b]{2}{*}{$\mathrm{PR}(\%)$} & \multirow[b]{2}{*}{ P-value } \\
\hline & & - & + & ++ & +++ & & \\
\hline Gastritis & 73 & 59 & 8 & 4 & 2 & 19.2 & $<0.001$ \\
\hline IM & 86 & 66 & 13 & 5 & 2 & 23.3 & \\
\hline Adenoma & 63 & 41 & 13 & 7 & 2 & 34.9 & \\
\hline Gastric carcinoma & 348 & 156 & 29 & 62 & 101 & 55.2 & \\
\hline
\end{tabular}

S100A4, S100 calcium-binding protein A4; PR, positive rate; IM, intestinal metaplasia.

Table II. Relationship between S100A4 expression and clinicopathological features of the gastric carcinoma cases.

\begin{tabular}{|c|c|c|c|c|c|c|c|}
\hline \multirow[b]{2}{*}{ Clinicopathological features } & \multirow[b]{2}{*}{$\mathrm{N}$} & \multicolumn{4}{|c|}{ S100A4 expression } & \multirow[b]{2}{*}{ PR $(\%)$} & \multirow[b]{2}{*}{ P-value } \\
\hline & & - & + & ++ & +++ & & \\
\hline Age (years) & & & & & & & 0.277 \\
\hline$<55$ & 139 & 67 & 12 & 23 & 37 & 51.8 & \\
\hline$\geq 55$ & 209 & 89 & 17 & 39 & 64 & 57.4 & \\
\hline Gender & & & & & & & 0.183 \\
\hline Male & 248 & 102 & 27 & 46 & 73 & 58.9 & \\
\hline Female & 100 & 54 & 2 & 16 & 28 & 46.0 & \\
\hline Tumor size $(\mathrm{cm})$ & & & & & & & $<0.001$ \\
\hline$\leq 4$ & 120 & 84 & 4 & 11 & 21 & 30.0 & \\
\hline$>4$ & 228 & 72 & 25 & 51 & 80 & 68.4 & \\
\hline Depth of invasion & & & & & & & $<0.001$ \\
\hline Tis-T1 & 33 & 25 & 2 & 2 & 4 & 24.2 & \\
\hline $\mathrm{T} 2-\mathrm{T} 4$ & 315 & 131 & 27 & 60 & 97 & 58.4 & \\
\hline Lymphatic invasion & & & & & & & $<0.001$ \\
\hline - & 192 & 116 & 14 & 20 & 42 & 39.6 & \\
\hline+ & 156 & 40 & 15 & 42 & 59 & 74.4 & \\
\hline Venous invasion & & & & & & & 0.44 \\
\hline- & 245 & 135 & 17 & 32 & 61 & 44.9 & \\
\hline+ & 103 & 21 & 12 & 30 & 40 & 79.6 & \\
\hline $\mathrm{LN}$ & & & & & & & 0.002 \\
\hline- & 138 & 83 & 4 & 12 & 39 & 39.8 & \\
\hline+ & 210 & 73 & 25 & 50 & 62 & 65.2 & \\
\hline TNM staging & & & & & & & $<0.001$ \\
\hline I & 6 & 6 & 0 & 0 & 0 & 0.0 & \\
\hline II & 60 & 48 & 2 & 4 & 6 & 20.0 & \\
\hline III & 104 & 50 & 5 & 15 & 34 & 51.9 & \\
\hline IV & 178 & 52 & 22 & 43 & 61 & 70.8 & \\
\hline Lauren's classification & & & & & & & $<0.001$ \\
\hline IT & 203 & 131 & 7 & 23 & 42 & 35.5 & \\
\hline DT & 145 & 25 & 22 & 39 & 59 & 82.8 & \\
\hline
\end{tabular}

S100A4, S100 calcium-binding protein A4; PR, positive rate; Tis, carcinoma in situ; $\mathrm{T} 1$, lamina propria and submucosa; T2, muscularis propria and subserosa; T3, exposure to serosa; T4, invasion into serosa; TNM, tumor-node-metastasis LN, lymph node metastasis; IT, intestinal-type; DT, diffuse-type.

lymphatic and venous invasion, lymph node metastasis, and TNM staging $($ all $\mathrm{P}<0.05)$ in carcinoma patients. Age and gender, however, had no influence on S100A4 expression in the carcinoma patients $(\mathrm{P}>0.05)$. S100A4 expression was higher in intestinal-type (IT) carcinomas than that in diffuse-type (DT) carcinomas $(\mathrm{P}<0.001)$. 

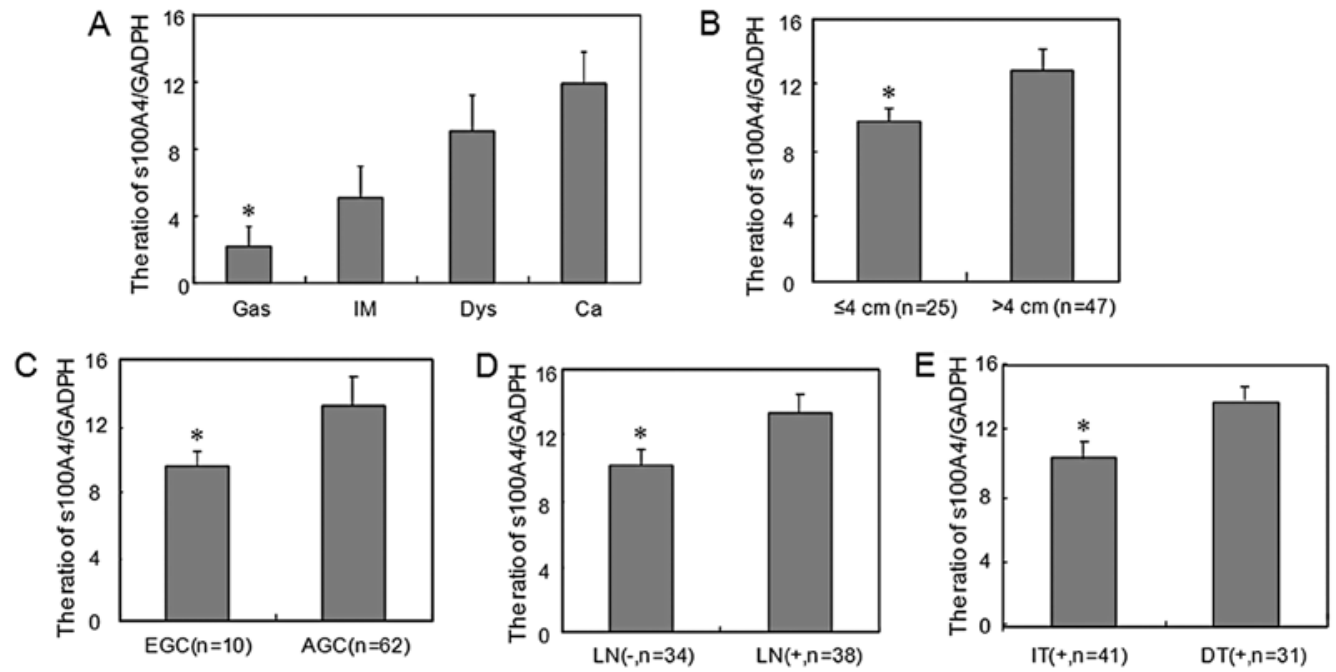

Figure 2. S100A4 mRNA expression level during gastric carcinogenesis and its correlation with clinicopathological features of carcinoma. (A) S100A4 mRNA was detectable in gastritis (Gas), intestinal metaplasia (IM), dysplasia (Dys), and carcinoma (Ca) samples, as revealed by real-time RT-PCR analysis, and it gradually increased from Gas, IM, Dys to $\mathrm{Ca}\left({ }^{*} \mathrm{P}<0.05\right.$; Ca vs. Gas). S100A4 mRNA expression was higher in gastric carcinomas that showed (B) a larger diameter ("P<0.05; $>4$ cm vs. $\leq 4 \mathrm{~cm}$ ), (C) deeper invasion ("P<0.05; AGC vs. EGC), (D) frequent lymph node metastasis ["P<0.05; $\mathrm{LN}(+)$ vs. $\leq \mathrm{LN}(-)$ ], and (E) intestinal-type ("P<0.05; DT vs. IT). Data are presented as means \pm SD. EGC, early gastric cancer; AGC, advanced gastric cancer; LN, lymph node metastasis; IT, intestinal-type; DT, diffuse-type.

A
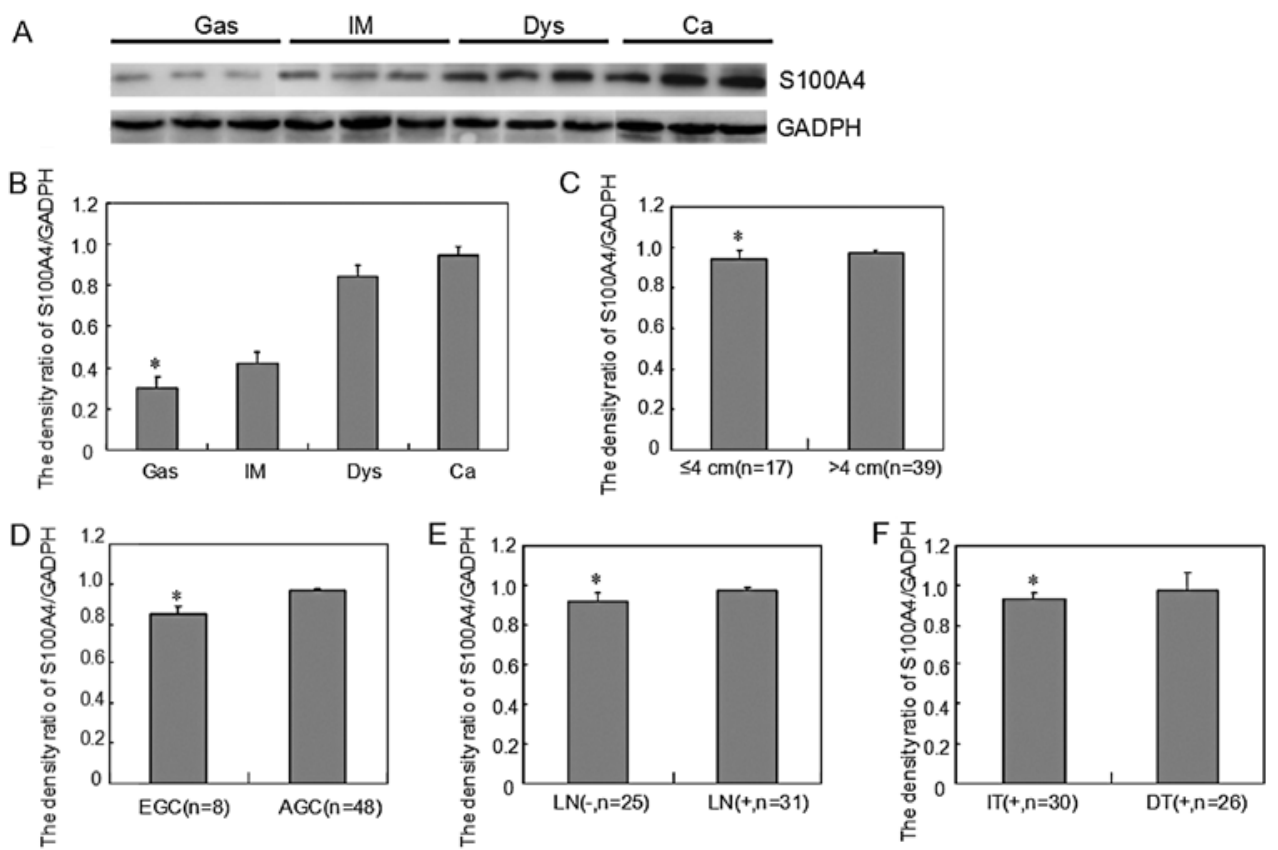

Figure 3. S100A4 protein expression level during gastric carcinogenesis and its correlation with clinicopathological features of carcinoma. (A) Cell lysates were separated on a 15\% SDS-polyacrylamide gel, transferred to a Hybond membrane and probed with anti-S100A4 (29 kDa), using GADPH (37 kDa) as an internal control. (B) Densitometric analysis demonstrated S100A4 expression in gastritis (Gas), intestinal metaplasia (IM), dysplasia (Dys), and carcinoma (Ca) specimens, and the S1004A protein expression level gradually increased from Gas, IM, Dys to Ca ("P $<0.05$, Ca vs. Gas). S100A4 protein expression was higher in gastric carcinomas that showed (C) a larger diameter ( $(\mathrm{P}<0.05,>4 \mathrm{~cm}$ vs. $\leq 4 \mathrm{~cm})$, (D) deeper invasion ( ${ }^{*} \mathrm{P}<0.05$, AGC vs. EGC), (E) frequent lymph node metastasis [" $\mathrm{P}<0.05, \mathrm{LN}(+)$ vs $\leq \mathrm{LN}(-)]$, and $(\mathrm{F})$ intestinal-type ("P $<0.05$, DT vs. IT). Data are presented as means \pm SD. EGC, early gastric cancer; AGC, advanced gastric cancer; LN, lymph node metastasis; IT, intestinal-type; DT, diffuse-type.

Real-time RT-PCR and western blot analysis for S100A4 expression and its correlation with clinicopathological features of gastric carcinoma. We designed S100A4-specific primers and performed real-time RT-PCR to quantify the mRNA expression level of S100A4 by using the housekeeping gene GAPDH as an internal control. The S100A4 mRNA expression was upregulated in the following order: gastritis $<$ IM $<$ dysplasia < carcinoma $(\mathrm{P}<0.001)$ (Fig. 2). Higher S100A4 mRNA expression was observed in gastric carcinomas that showed a larger diameter $(>4 \mathrm{~cm})$, deeper invasion, and frequent lymph node metastasis, and in IT carcinoma $(\mathrm{P}<0.05)$. These findings were also supported by the evaluation of S100A4 protein expression as assessed by western blot analysis (Fig. 3). 
Table III. Multivariate analysis of clinicopathological variables to determine the survival of gastric carcinoma cases.

\begin{tabular}{llr}
\hline Clinicopathological parameters & Relative risk (95\% CI) & P-value \\
\hline Age ( $\geq 55$ years) & $1.399(0.992-1.898)$ & 0.057 \\
Gender (female) & $0.729(0.519-1.241)$ & 0.087 \\
Depth of invasion (T2-4) & $2.288(1.689-6.234)$ & 0.048 \\
Lymphatic invasion (+) & $1.528(1.055-2.367)$ & 0.049 \\
Venous invasion (+) & $1.672(1.063-2.723)$ & 0.041 \\
Lymph node metastasis (+) & $2.042(1.114-3.931)$ & 0.027 \\
TNM staging (III-IV) & $5.584(2.126-12.045)$ & $<0.001$ \\
Lauren's classification (intestinal/diffuse) & $1.119(0.886-1.393)$ & 0.287 \\
S100A4 expression (+ - +++) & $1.522(1.325-4.236)$ & 0.045
\end{tabular}

CI, confidence interval; TNM, tumor-node-metastasis.

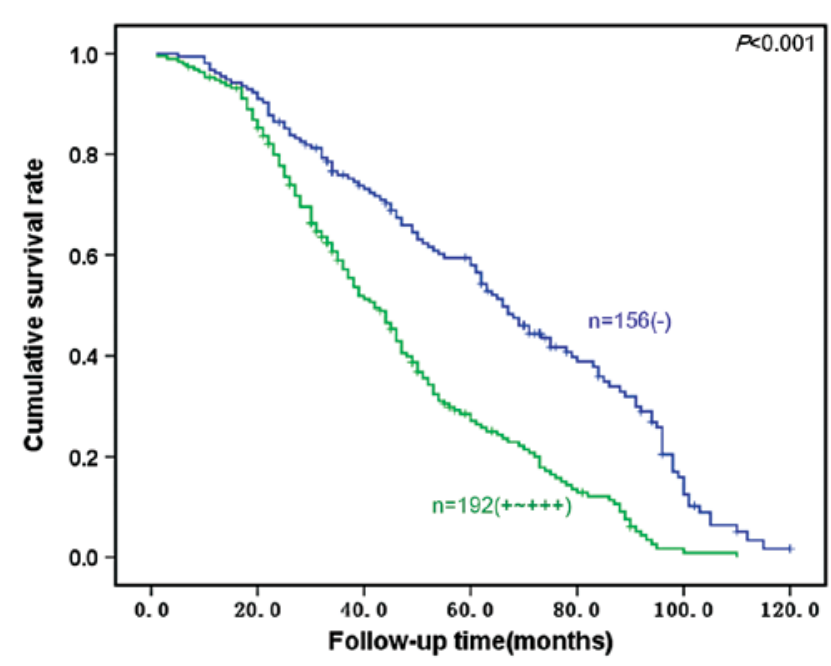

Figure 4. Correlation between S100A4 expression status and prognosis of gastric carcinoma patients. Kaplan-Meier curves were plotted to determine cumulative survival rate of patients with gastric carcinomas based on S100A4 expression. The cumulative survival rate of patients with weak or moderate S100A4 expression (green curve) was lower than that of patients not expressing S100A4 (blue curve; $\mathrm{P}<0.001$ ).

Correlation between S100A4 expression and survival of gastric carcinoma patients. Follow-up information was available on 348 gastric carcinoma patients for periods ranging from 1 month to 10.1 years (median, 65.1 months). Fig. 4 shows survival curves stratified according to S100A4 protein expression in the gastric carcinomas. Univariate analysis using the Kaplan-Meier method indicated the cumulative survival rate of patients with weak or moderate S100A4 expression $(n=192)$ to be clearly lower than that of patients not expressing S100A4 $(\mathrm{n}=156 ; \mathrm{P}<0.05)$.

Multivariate analysis using Cox's proportional hazard model was conducted to determine the independent prognostic effects of the various clinicopathological parameters. Our results demonstrated that depth of invasion $(\mathrm{P}=0.048)$, lymphatic and venous invasion $(\mathrm{P}=0.049$ and 0.041 , respectively), lymph node metastasis $(\mathrm{P}=0.027)$, TNM staging $(\mathrm{P}<0.001)$, and S100A4 expression $(\mathrm{P}=0.045)$ were indepen- dent factors for the poor prognosis of gastric carcinoma (all $\mathrm{P}<0.05$ ) (Table III).

\section{Discussion}

In the present study, the S100A4 protein was detected in the cytoplasm and nuclei of gastric lesions, which is in agreement with a previous report $(24,25)$. S100A4 is a transcriptional factor that can translocate from the nucleus to the cytosol under certain physiological or pathological conditions. Here, we found gradually increased expression of S100A4 at both the mRNA and protein level in the following ascending order: gastritis $<$ IM < dysplasia < carcinoma. These results are in line with other reports regarding clear cell renal cell carcinoma (26), esophageal squamous cell carcinoma (ESCC) $(27,28)$, colorectal carcinoma (29), breast cancer (30) and bladder cancer (31). IM is believed to be an adaptive condition for an injured and inflamed gastric epithelium and can develop into globoid dysplasia, which is closely linked to signet ring cell carcinoma, as revealed by its morphological appearance and biological characteristics (32). Pathological and genetic observations demonstrated that gastric dysplasia precedes the majority of carcinomas, can undergo malignant transformation, and is classified into cryptal, globoid, regenerative, and adenomatous subtypes (33). Our study is the first to suggest that higher S100A4 expression may contribute to carcinogenesis. Based on previous literature reports $(34,35)$, S100A4 overexpression may result in hypomethylation of the $\mathrm{CpG}$ sites in the first intron of the S100A4 gene or simply a result of S100A4 stimulation under a hypoxic microenvironment.

To elucidate the role of the S100A4 protein in the progression of gastric carcinoma, we tested whether the expression status of S100A4 was associated with the aggressive behavior of carcinomas. We found that the S100A4 mRNA and protein expression was positively linked to tumor size, depth of invasion, lymphatic and venous invasion, lymph node metastasis, and TNM staging in gastric carcinomas, which supported the previous findings of Feng et al (36). It has been reported that cytoplasmic expression of the S100A4 protein was positively correlated with depth of invasion and lymph node metastasis, whereas the nuclear expression of S100A4 protein was positively 
correlated with the depth of invasion and perineural invasion of colorectal cancer (37). The positive relationship between S100A4 expression and aggressiveness was also observed in advanced-stage endometrial cancer (38) and bladder cancer (31). These findings suggest that S100A4 overexpression is involved in the growth, invasion, and metastasis of gastric carcinoma and may serve as an indicator of the aggressiveness of gastric carcinoma tumors in clinicopathological practice. In the light of our present findings, we speculate that S100A4 upregulation may participate in the progression of gastric cancer by reversing the aggressive phenotype of cancer cells.

S100A4 is known to regulate migratory and invasive behavior of human ESCC cells through the downregulation by E-cadherin expression and modulation of the AKT/Slug pathway $(28,39)$. Sack et al (40) reported that S100A4-induced cell motility and metastasis are inhibited by the $\mathrm{Wnt} / \beta$-catenin pathway inhibitor calcimycin in colon cancer cells. Zhang et al (27) reported that S100A4 mediates the cell invasion and metastasis of ESCC via the regulation of MMP-2 and E-cadherin activity. Shen et al (41) found that S100A4 protects gastric cancer cells from anoikis through regulation of $\alpha \mathrm{v}$ and a 5 integrins. Hua et al (42) demonstrated that inhibition of S100A4 promotes apoptosis and suppresses proliferation of BGC823 gastric cancer cells in vitro and in vivo. Xie et al (43) documented that S100A4 mediates endometrial cancer invasion, and induction of S100A4 was associated with the activation of Smads in tumor growth factor (TGF)- $\beta 1$ signaling. Based on these data and our current findings, we hypothesize that S100A4 upregulation enhances the aggressive phenotypes and behavior of malignant cancers through the $\mathrm{Wnt} / \beta$-catenin or TGF- $\beta$ signaling pathways.

Although gastric cancer is a malignant tumor originating from the same type of gastric epithelium, its morphological features vary substantially among individual patients. According to Lauren's classification, IT carcinomas are characterized by cohesive carcinoma cells forming glandlike tubular structures with expanding or infiltrative growth patterns, and include well- and moderately differentiated adenocarcinomas. DT carcinomas display less apparent or no cell adhesion and contain poorly differentiated signet-ring cell carcinoma $(22,23)$. In the present study, we noted that the protein and mRNA expression of S100A4 was lower in IT carcinoma compared to that in DT, indicating that S100A4 may play an important role in IT carcinogenesis, but less so in the de novo carcinogenic pathway, and may serve as the molecular basis for distinction between the two types of carcinomas.

In the present study, we found that S100A4 expression was inversely correlated with the favorable prognosis of patients with gastric carcinoma, which was consistent with previous reports $(24,25)$. Cox's proportional risk analysis indicated that the depth of invasion, lymphatic or venous invasion, lymph node metastasis, TNM staging, and S100A4 expression were independent factors for the poor prognosis of gastric carcinoma patients. These findings suggest that S100A4 expression is an independent prognostic factor for gastric carcinoma patients. Kho et al (44) found that only cytoplasmic S100A4 staining, but not nuclear staining, of the frontal tissue was associated with poor survival of patients with stage $C$ colonic cancer. In contrast, Kang et al (37) showed that nuclear expression of the S100A4 protein was found to be an independent prognostic factor for poor survival of colorectal cancer patients. Similar results were also obtained in pancreatic cancer (45), renal cell carcinoma (46), bladder cancer (31) and lung squamous cell carcinoma (47). These findings suggest that S100A4 expression is an independent and reliable indicator for a less favorable prognosis of gastric cancer patients.

In summary, upregulation of S100A4 may play an important role in the malignant transformation of gastric epithelial cells and is positively related to growth, invasion, metastasis, and prognosis of gastric carcinomas. Thus, S100A4 may be considered as a promising marker to indicate the aggressive behavior of gastric carcinomas. The distinct expression of S100A4 in DT gastric carcinoma can be employed to differentiate between the intestinal- and diffuse-type carcinomas and may serve as a molecular feature that distinguishes the two types of carcinomas.

\section{Acknowledgements}

The study was supported by the Nature Science Foundation of Liaoning Province (201202279).

\section{References}

1. Crew KD and Neugut AI: Epidemiology of upper gastrointestinal malignancies. Semin Oncol 31: 450-464, 2004.

2. Yu M, Zheng HC, Xia P, et al: Comparison in pathological behaviours and prognosis of gastric cancers from general hospitals between China and Japan. Indian J Med Res 132: 295-302, 2010.

3. Heizmann CW, Fritz G and Schafer BW: S100 proteins: structure, functions and pathology. Front Biosci 7: d1356-d1368, 2002.

4. Tsai WC, Lin YC, Tsai ST, et al: Lack of modulatory function of coding nucleotide polymorphism S100A2_185G $>$ A in oral squamous cell carcinoma. Oral Dis 17: 283-290, 2011.

5. Sherbet GV and Lakshmi MS: S100A4 (MTS1) calcium binding protein in cancer growth, invasion and metastasis. Anticancer Res 18: 2415-2421, 1998.

6. Kwak JM, Lee HJ, Kim SH, et al: Expression of protein S100A4 is a predictor of recurrence in colorectal cancer. World $\mathrm{J}$ Gastroenterol 16: 3897-3904, 2010.

7. Boye K and Maelandsmo GM: S100A4 and metastasis: a small actor playing many roles. Am J Pathol 176: 528-535, 2010.

8. Mishra SK, Siddique HR and Saleem M: S100A4 calciumbinding protein is key player in tumor progression and metastasis: preclinical and clinical evidence. Cancer Metastasis Rev 31: 163-172, 2012.

9. Zheng X, Yao Y, Xu Q, Tu K and Liu Q: Evaluation of gliomaassociated oncogene 1 expression and its correlation with the expression of sonic hedgehog, E-cadherin and S100a4 in human hepatocellular carcinoma. Mol Med Rep 3: 965-970, 2010.

10. Lo JF, Yu CC, Chiou SH, et al: The epithelial-mesenchymal transition mediator S100A4 maintains cancer-initiating cells in head and neck cancers. Cancer Res 71: 1912-1923, 2011.

11. Jenkinson SR, Barraclough R, West CR and Rudland PS: S100A4 regulates cell motility and invasion in an in vitro model for breast cancer metastasis. Br J Cancer 90: 253-262, 2004.

12. Takenaga K, Nakamura Y and Sakiyama S: Expression of antisense RNA to S100A4 gene encoding an S100-related calcium-binding protein suppresses metastatic potential of high-metastatic Lewis lung carcinoma cells. Oncogene 14: 331-337, 1997.

13. Maelandsmo GM, Hovig E, Skrede M, et al: Reversal of the in vivo metastatic phenotype of human tumor cells by an anti-CAPL (mts1) ribozyme. Cancer Res 56: 5490-5498, 1996.

14. Garrett SC, Varney KM, Weber DJ and Bresnick AR: S100A4, a mediator of metastasis. J Biol Chem 281: 677-680, 2006.

15. Helfman DM, Kim EJ, Lukanidin E and Grigorian M: The metastasis associated protein S100A4: role in tumour progression and metastasis. Br J Cancer 92: 1955-1958, 2005.

16. Takenaga K, Nakamura Y, Sakiyama S, Hasegawa Y, Sato K and Endo H: Binding of pEL98 protein, an S100-related calciumbinding protein, to nonmuscle tropomyosin. J Cell Biol 124: $757-768,1994$. 
17. Watanabe $\mathrm{Y}$, Usada N, Minami $\mathrm{H}$, et al: Calvasculin, as a factor affecting the microfilament assemblies in rat fibroblasts transfected by src gene. FEBS Lett 324: 51-55, 1993.

18. Kriajevska MV, Cardenas MN, Grigorian MS, Ambartsumian NS, Georgiev GP and Lukanidin EM: Non-muscle myosin heavy chain as a possible target for protein encoded by metastasisrelated mts-1 gene. J Biol Chem 269: 19679-19682, 1994.

19. Saleem M, Kweon MH, Johnson JJ, et al: S100A4 accelerates tumorigenesis and invasion of human prostate cancer through the transcriptional regulation of matrix metalloproteinase 9. Proc Natl Acad Sci USA 103: 14825-14830, 2006.

20. Bjørnland K, Winberg JO, Odegaard OT, et al: S100A4 involvement in metastasis: deregulation of matrix metalloproteinases and tissue inhibitors of matrix metalloproteinases in osteosarcoma cells transfected with an anti-S100A4 ribozyme. Cancer Res 59: 4702-4708, 1999.

21. Sobin LH and Wittekind CH (eds): TNM Classification of Malignant Tumors. 6th edition. John Wiley \& Sons, Hoboken, $\mathrm{NJ}, 2002$.

22. Zheng H, Takahashi H, Murai Y, et al: Pathobiological characteristics of intestinal and diffuse-type gastric carcinoma in Japan: an immunostaining study on the tissue microarray. J Clin Pathol 60: 273-277, 2007.

23. Zheng HC, Li XH, Hara T, et al: Mixed-type gastric carcinomas exhibit more aggressive features and indicate the histogenesis of carcinomas. Virchows Arch 452: 525-534, 2008.

24. Wang YY, Ye ZY, Zhao ZS, Tao HQ and Chu YQ: High-level expression of S100A4 correlates with lymph node metastasis and poor prognosis in patients with gastric cancer. Ann Surg Oncol 17: 89-97, 2010.

25. Kim YJ, Kim MA, Im SA, et al: Metastasis-associated protein S100A4 and p53 predict relapse in curatively resected stage III and IV (M0) gastric cancer. Cancer Invest 26: 152-158, 2008.

26. Yang H, Zhao K, Yu Q, Wang X, Song Y and Li R: Evaluation of plasma and tissue S100A4 protein and mRNA levels as potential markers of metastasis and prognosis in clear cell renal cell carcinoma. J Int Med Res 40: 475-485, 2012.

27. Zhang HY, Zheng XZ, Wang XH, Xuan XY, Wang F and Li SS: S100A4 mediated cell invasion and metastasis of esophagea squamous cell carcinoma via the regulation of MMP-2 and E-cadherin activity. Mol Biol Rep 39: 199-208, 2012.

28. Chen D, Zheng XF, Yang ZY, et al: S100A4 silencing blocks invasive ability of esophageal squamous cell carcinoma cells. World J Gastroenterol 18: 915-922, 2012.

29. Kim JH, Kim CN, Kim SY, et al: Enhanced S100A4 protein expression is clinicopathologically significant to metastatic potential and p53 dysfunction in colorectal cancer. Oncol Rep 22: 41-47, 2009.

30. Ismail NI, Kaur G, Hashim H and Hassan MS: S100A4 overexpression proves to be independent marker for breast cancer progression. Cancer Cell Int 8: 12, 2008.

31. Matsumoto K, Irie A, Satoh T, et al: Expression of S100A2 and S100A4 predicts for disease progression and patient survival in bladder cancer. Urology 70: 602-607, 2007.

32. Zheng HC, Xu XY, Yu M, Takahashi H, Masuda S and Takano Y: The role of Reg IV gene and its encoding product in gastric carcinogenesis. Hum Pathol 41: 59-69, 2010.
33. Zhang YC: Geographic pathology of gastric dysplasia in China. Semin Surg Oncol 10: 100-106, 1994.

34. Horiuchi A, Hayashi T, Kikuchi N, et al: Hypoxia upregulates ovarian cancer invasiveness via the binding of HIF-1 $\alpha$ to a hypoxia-induced, methylation-free hypoxia response element of S100A4 gene. Int J Cancer 131: 1755-1767, 2012.

35. Liu J, Guo Y, Fu S, Yang M, Sun KL and Fu WN: Hypomethylation-induced expression of S100A4 increases the invasiveness of laryngeal squamous cell carcinoma. Oncol Rep 23: 1101-1107, 2010.

36. Feng LZ, Zheng XY, Zhou LX, et al: Correlation between expression of S100A4 and VEGF-C, and lymph node metastasis and prognosis in gastric carcinoma. J Int Med Res 39: 1333-1343, 2011.

37. Kang YG, Jung CK, Lee A, Kang WK, Oh ST and Kang CS: Prognostic significance of S100A4 mRNA and protein expression in colorectal cancer. J Surg Oncol 105: 119-124, 2012.

38. Xie R, Loose DS, Shipley GL, Xie S, Bassett RL Jr and Broaddus RR: Hypomethylation-induced expression of S100A4 in endometrial carcinoma. Mod Pathol 20: 1045-1054, 2007.

39. Zhang K, Zhang M, Zhao H, Yan B, Zhang D and Liang J: S100A4 regulates motility and invasiveness of human esophageal squamous cell carcinoma through modulating the AKT/Slug signal pathway. Dis Esophagus 25: 731-739, 2012.

40. Sack U, Walther W, Scudiero D, et al: S100A4-induced cell motility and metastasis is restricted by the Wnt $/ \beta$-catenin pathway inhibitor calcimycin in colon cancer cells. Mol Biol Cell 22: 3344-3354, 2011.

41. Shen W, Chen D, Fu H, Liu S, Sun K and Sun X: S100A4 protects gastric cancer cells from anoikis through regulation of $\alpha \mathrm{V}$ and $\alpha 5$ integrin. Cancer Sci 102: 1014-1018, 2011.

42. Hua J, Chen D, Fu H, et al: Short hairpin RNA-mediated inhibition of S100A4 promotes apoptosis and suppresses proliferation of BGC823 gastric cancer cells in vitro and in vivo. Cancer Lett 292: 41-47, 2010.

43. Xie R, Schlumbrecht MP, Shipley GL, Xie S, Bassett RL Jr and Broaddus RR: S100A4 mediates endometrial cancer invasion and is a target of TGF-betal signaling. Lab Invest 89: 937-947, 2009.

44. Kho PS, Jankova L, Fung CL, et al: Overexpression of protein S100A4 is independently associated with overall survival in stage $\mathrm{C}$ colonic cancer but only in cytoplasm at the advancing tumour front. Int J Colorectal Dis 27: 1409-1417, 2012.

45. Ikenaga $\mathrm{N}$, Ohuchida $\mathrm{K}$, Mizumoto $\mathrm{K}$, et al: S100A4 mRNA is a diagnostic and prognostic marker in pancreatic carcinoma. J Gastrointest Surg 13: 1852-1858, 2009.

46. Bandiera A, Melloni G, Freschi M, et al: Prognostic factors and analysis of S100a4 protein in resected pulmonary metastases from renal cell carcinoma. World J Surg 33: 1414-1420, 2009.

47. Tsuna M, Kageyama S, Fukuoka J, et al: Significance of S100A4 as a prognostic marker of lung squamous cell carcinoma. Anticancer Res 29: 2547-2554, 2009. 